\title{
O LIVRO DIDÁTICO NA FORMAÇÃO DO PROFESSOR DE INGLÊS: ALGUMAS REFLEXÕES A PARTIR DAS PERCEPÇÕES DE FORMADORES
}

\author{
Textbooks in English language teacher education programs: some \\ reflections based on the perceptions of educators
}

\author{
Elisângela Lorena LIBERATTI \\ Universidade Estadual de Londrina \\ elislieratti@hotmail.com \\ https://orcid.org/0000-0002-2800-5810 \\ Isadora Teixeira MORAES \\ Universidade Estadual de Londrina \\ isatmoraes@gmail.com \\ https://orcid.org/0000-0002-5393-286X
}

\begin{abstract}
RESUMO: O livro didático (LD) se faz presente na maioria dos contextos educacionais, mas é frequentemente usado de maneira indiscriminada (SILVA, 1996), e isso pode ser resultado de lacunas na formação do professor (CONSOLO, 1990). Em contextos em que a aprendizagem envolve a transmissão de conhecimentos, esse uso do LD é coerente. Atualmente, no entanto, a formação de professores é crítico-reflexiva (GIMENEZ, 1999; LIBERALI, 2004), e advoga em favor da construção de conhecimentos sobre ensino e aprendizagem. Levando em conta o conceito de simetria invertida (BRASIL, 2002), que preconiza que o professor tenha uma formação consistente com a que se espera dele no futuro, neste artigo investigamos as percepções de professores formadores quanto ao uso do LD para o ensino de inglês em cursos de Letras de universidades estaduais do Paraná. A partir disso, buscamos refletir sobre a coerência do uso (ou não uso) do LD nesse contexto, considerando as demandas atuais de ensino, bem como as possíveis implicações desse uso para a formação crítica dos futuros docentes. Para tal, foram enviados questionários aos professores dos cursos, via e-mail. Das dez respostas que obtivemos, três respondentes apontaram a utilização de um LD, o que permeou nossa análise e discussão. PALAVRAS-CHAVE: Ensino de língua inglesa; Formação de professores; Livro didático.
\end{abstract}

ABSTRACT: Despite being found in most educational contexts, textbooks are often used indiscriminately (SILVA, 1996). Among other factors, this is a consequence of some gaps in teacher education (CONSO- 
LO, 1990). In traditional teaching models, where learning involves the transmission of knowledge, using textbooks can be regarded as a coherent practice. Nowadays, however, teacher education is a critical-reflexive process (GIMENEZ, 1999; LIBERALI, 2004), as it advocates in favor of building knowledge about teaching and learning. Considering the concept of inverted symmetry (BRASIL, 2002), which prioritizes a teacher training consistent with what is expected of these teachers in the future, in this article we investigate the perceptions of teacher educators regarding the use of textbooks for teaching English in English teacher education courses at Paraná's state universities. Our aim here is to reflect on the coherence of the use of textbooks in such contexts, considering current teaching demands, as well as the possible implications of this use for critically educating these future teachers. In that sense, questionnaires were sent to Professors of the courses abovementioned via e-mail. Considering the ten responses obtained, three respondents indicated the use of textbooks, which permeates our analysis and discussion. KEYWORDS: English teaching; Teacher education; Textbooks.

\section{INTRODUÇ̃̃̃O}

Uma imagem tradicional que se tem do professor é deste próximo ao quadro negro, de frente para seus alunos (silenciosos a maior parte do tempo), ditando regras e fornecendo explicações, sempre com um livro didático em mãos (SILVA, 1996). Apesar dos processos inacabados (e inacabáveis) de mudanças pelos quais passa a educação, essa imagem fossilizada do professor parece não mudar - em especial no que tange ao livro didático.

Historicamente falando, o livro didático (doravante, LD) só passou a fazer parte da sala de aula após a invenção da imprensa e, ainda assim, era comum que apenas o professor tivesse acesso a ele (PAIVA, 2009). Atualmente, no entanto, é difícil imaginar um contexto de ensino que não faça uso desse recurso. Porém, como toda ferramenta educacional, o LD não teve uma história livre de críticas, permanecendo, até os dias atuais, alvo de controvérsias. Diversos autores (CONSOLO, 1990; PESSOA, 2009; SOUZA; STEFANELLO; SPILMANN, 2010) concordam, por exemplo, que em muitos contextos o LD é utilizado de forma indiscriminada, o que é resultado de lacunas na formação do professor. Deste modo, torna-se importante estudar esse instrumento, levando em conta todas as suas potencialidades e limitações nos mais diversos contextos.

Se pensarmos no conceito de simetria invertida (BRASIL, 2002), discutido na próxima seção, a formação do professor ocorre em um ambiente que deveria servir de 
espelho daquilo que se espera dele; isto é, esse futuro professor deve ter uma formação coerente com o trabalho que se almeja que ele realize em sala de aula posteriormente. Como formadoras de professores de língua inglesa (LI), voltamos nossa atenção para nossa própria prática, e nos perguntamos que ações estaríamos tomando ou deixando de tomar para contribuir para este cenário. Na era atual do ensino de línguas, os modelos de formação de professores almejam uma educação emancipatória e libertadora (FREIRE, 1985), entendendo a língua como prática social (BAKHTIN, 2003), e o processo de aprendizagem-avaliação-ensino ${ }^{1}$, como transformador e não-linear. Será que nós e nossos colegas estamos cumprindo todas estas premissas?

No que concerne ao ensino de línguas estrangeiras, Sarmento e Lamberts (2017) concluem, em um mapeamento de estudos sobre o LD, que a maioria dos trabalhos na área trata da análise, da avaliação, da escolha e do design de LDs. Porém, poucos tratam do LD no Ensino Superior (SOUZA; MATE; PORTO, 2011) e, menos ainda, de seu uso para o ensino de línguas em um contexto de formação de professores. Ensinar uma língua é uma tarefa desafiadora por si só, quem dirá ensiná-la para aqueles que, futuramente, também serão professores de línguas. Nesse sentido, o uso de um LD pode facilitar essa complexa tarefa - ou, por outro lado, pode ser mais um fator de estagnação do ensino.

Dessa forma, este trabalho tem como objetivo investigar as percepções de professores formadores quanto ao uso do LD para o ensino de inglês em cursos de Letras e, a partir disso, tecer reflexões sobre as possíveis implicações desse uso (ou não uso) para a formação de professores de línguas críticos e reflexivos (GIMENEZ, 1999; LIBERALI, 2004). Afunilamos nosso contexto de pesquisa para as universidades estaduais do Paraná, visto que este é também nosso contexto de atuação e, portanto, mais próximo da nossa realidade.

Na seção seguinte, abordamos a relação entre o livro didático, as teorias de ensino e a formação do professor. Em seguida, explicaremos como foi feita nossa coleta de dados, para finalmente passarmos para a análise dos resultados. Por fim, tecemos considerações quanto ao caminho percorrido, limitações do trabalho e possibilidades de pesquisas futuras.

\footnotetext{
${ }^{1}$ Utilizaremos o termo desta forma a partir daqui por entendermos a) a aprendizagem como orientadora do processo (LEUNG et al., 2018) e b) a avaliação como integradora da aprendizagem e do ensino (SCARAMUCCI, 2006).
} 


\section{O LIVRO DIDÁTICO, AS TEORIAS DE ENSINO E A FORMAÇÃO DO PRO- FESSOR}

Os primeiros livros didáticos foram as gramáticas (PAIVA, 2009), indo ao encontro do primeiro método conhecido de ensino de línguas, o da gramática e da tradução (LEFFA, 1988). Esse método, inclusive, só se tornou popular por causa de um LD: o Orbis Pictus, um livro para crianças publicado em Nuremberg em 1658 (KELLY, 1969, p. 260 apud PAIVA, 2009, p. 20-21). O livro trazia explicações gramaticais simples, facilitando a aprendizagem de línguas estrangeiras e diferenciando-se, portanto, de LDs com base em textos literários, como os de grego ou latim. Essa inovação tornou o Orbis Pictus um grande sucesso, e ele serviu de modelo para LDs posteriores. Aqueles usados no Brasil na primeira metade do século XX também procuraram facilitar o entendimento da gramática, revelando o conceito de língua vigente: língua como estrutura, como um conjunto de regras a serem dominadas (PAIVA, 2009).

O tempo passou, as distâncias diminuíram com os diversos meios de transporte disponíveis, a produção oral de um falante nativo pôde ser captada por um gravador, e a $2^{\mathrm{a}}$ Guerra Mundial exigiu que os soldados soubessem falar e não somente escrever ou traduzir na língua estrangeira. Essas (dentre outras) mudanças históricas, econômicas, tecnológicas e sociais implicaram necessidades de aprendizagem de línguas diferentes, o que pode ser atestado pela emergência de diversos métodos de ensino de línguas (LEFFA, 1988). Ora a ênfase era na gramática, ora na produção oral, ora na comunicação, ora nas necessidades específicas do(s) aluno(s). O LD acompanhou essas tendências, incentivando e reforçando determinadas abordagens ${ }^{2}$ e - por que não - capitalizando-as, de certa forma.

A educação sempre foi influenciada pelos modelos econômicos vigentes (DARLING-HAMMOND, 2006), e no caso do LD não poderia ser diferente. Muito mais que um instrumento de apoio didático, ele pode ser fonte de capital para editoras e franquias, além de promover "a circulação de ideias, valores e comportamentos desejados em determinados períodos" (SOUZA; MATE; PORTO, 2011, p. 873). A união das esferas pedagógica, econômica e política forma esse caráter ideológico (SOUZA; MATE; PORTO, 2011).

No Ensino Superior, o LD passou a ganhar espaço com a reforma universitária da década de 70, que resultou na expansão do número de vagas nos cursos de graduação (SOUZA; MATE; PORTO, 2011). A adoção repentina de um sistema de larga escala

\footnotetext{
2 Apesar de entendermos as diferenças entre 'abordagem' e 'método', como pontuado por Leffa (1988), escolhemos, neste texto, utilizar os dois termos como sinônimos.
} 
teve como consequência a massificação do ensino (SENISE, 2006) que, por sua vez, incentivou um modelo de trabalho com base na racionalidade técnica (SCHÖN, 1983; SILVA, 1996). Assim, os professores se tornaram aplicadores de teorias e currículos (PESSOA, 2009), não tendo flexibilidade para adaptar os materiais nem poder de escolha sobre os conteúdos abordados. Em um cenário como esse, no qual o professor ensina e os alunos aprendem, e o processo de aprendizagem é linear e direto, a adoção de uma ferramenta didática que apresenta conhecimentos estanques parece fazer sentido.

Atualmente, no entanto, os modelos de formação de professores procuram romper com tal racionalidade técnica (PESSOA, 2009), advogando em favor da construção de conhecimentos sobre ensino e aprendizagem (BRASIL, 2002) ao invés de uma mera transmissão de saberes de professor para aluno. A língua é vista como uma forma de existir no mundo; ela é dinâmica, dependente do contexto em que é utilizada e dos participantes da interação (BAKHTIN, 2003). É através da língua que agimos e existimos no mundo, que somos transformados e transformamos. Ela é sempre carregada de ideologias e, portanto, nunca neutra. São estes conceitos sobre língua que embasam a teoria de aprendizagem sociointeracionista (VYGOTSKY, 2003), que propõe uma reflexão no ensino de línguas, ao considerar o indivíduo como um ser social, apontando como essencial a sua interação com o ambiente em que vive e com as relações sociais para a construção do conhecimento e desenvolvimento psicológico (SOUZA; STEFANELLO; SPILMANN, 2010, p. 24). Por isso, ser professor de línguas é estar em constante mudança e evolução. O professor nos moldes atuais deve sempre refletir sobre sua própria prática, sendo amparado pelas teorias de ensino, em um eterno ciclo teoria-prática-teoria. Em outras palavras, o professor se torna pesquisador da sua própria prática, e é assim que desenvolve suas capacidades como docente (GIMENEZ, 1999). Este é o modelo reflexivo da formação de professores que se opõe ao da racionalidade técnica. A tão almejada mudança social só ocorrerá através de reflexões e questionamentos constantes, e professores devem colaborar "na luta política contra a hegemonia e a favor da diversidade e da igualdade de oportunidades" (PESSOA, 2009 , p. 58). Para isso, o professor precisa saber refletir sobre sua prática, apoiandose em seus conhecimentos sobre aprendizagem-avaliação-ensino de línguas e sobre seu contexto de atuação.

Nesse sentido, é papel da universidade criar oportunidades para o aluno de Letras desenvolver as habilidades necessárias para atuar na sua área, de modo que esse futuro profissional seja não só linguisticamente competente, mas também autônomo e crítico, além de "compreender sua formação profissional como processo contínuo, autônomo e permanente" (BRASIL, 2001, p. 30). 
Para certos autores (CONSOLO, 1990; PESSOA, 2009; SOUZA; STEFANELLO; SPILMANN, 2010), no entanto, vê-se no uso indiscriminado do LD o não cumprimento desse papel. É essa lacuna na formação do professor que por vezes o impede de utilizar o LD de maneira crítica, isto é, adaptando-o às necessidades do seu público-alvo, e entendendo-o como mais uma ferramenta didática à sua disposição.

O uso indiscriminado do LD pode, inclusive, acarretar uma inversão de papéis: este passa a ser central no processo de aprendizagem-avaliação-ensino, prescindindo do professor e sendo utilizado de maneira cega, como se trouxesse verdades inquestionáveis (PESSOA, 2009; SARMENTO; LAMBERTS, 2016; SILVA, 1996; SOUZA; MATE; PORTO, 2011). Em muitos casos, o LD é o único material de apoio do professor de línguas, o que acaba fortalecendo a "ditadura do livro didático" (TílIO, 2008, p. 124).

Por sermos professoras formadoras, nos questionamos, portanto, de que forma(s) poderíamos melhorar este cenário, fomentando assim uma reflexão sobre nossa própria prática. Levamos em conta o conceito de simetria invertida (BRASIL, 2002), que preconiza que o professor deve ter uma formação consistente com a que se espera dele no futuro; isto é, não deveria haver nos cursos de formação de professores uma postura no sentido de "faça o que eu digo, não faça o que eu faço".

Assim, ponderamos quais seriam as perspectivas de professores formadores quanto a essas questões, e de que maneira(s) eles concebem o papel do LD na formação do professor de línguas. Ressaltamos aqui que nossa intenção não é trazer à tona certa culpa por uma questão sistêmica, mas entender essas percepções como um primeiro passo na busca por melhorias que estejam dentro das nossas possibilidades e responsabilidades como formadoras.

No âmbito da avaliação educacional, por exemplo, Hoffmann (2000, p. 67) afirma que "no Ensino Superior, muitos professores não têm formação pedagógica, reproduzindo o modelo classificatório de suas escolas ou cursos universitários". Isso, segundo Sousa (2004 apud SILVA; FURTOSO, 2017), contribui para que nesse contexto haja muita resistência no que concerne a mudanças nas práticas avaliativas. É possível, assim, que tal resistência perpasse outras áreas da prática pedagógica do professor formador.

Os questionamentos aqui apresentados não são inéditos. Souza, Stefanello e Spilmann (2010) se propõem a refletir sobre "a prática de ensino e aprendizagem do inglês como língua estrangeira sob a perspectiva sociointeracionista, a formação do professor e o uso do livro didático (p. 23)". Através de entrevistas com professores de escolas de inglês de Santa Catarina, os autores mostram, em sua pesquisa, que "a insuficiente formação do professor na proposta sociointeracionista e a dependência do livro didático 
se retroalimentam (p. 23)". Isto é, quanto mais dependente do LD, menos o professor é capaz de trabalhar segundo uma abordagem sociointeracionista.

Pessoa (2009) também analisou o LD "na perspectiva da formação do professor e de uma visão sociointeracionista de linguagem (p. 54)”. A autora aplicou um questionário aberto a alunos do curso de Letras de modo a averiguar suas percepções sobre o uso dessa ferramenta didática em sua prática como professores. Ela conclui que os dados "permitem afirmar que eles [os alunos de Letras] ainda estão muito presos à concepção técnica de ensino de línguas e, em nosso entendimento, a utilização do livro didático contribui para isso (p. 67)". Por outro lado, a autora reconhece que o LD deve fazer parte do repertório técnico do professor, e que este pode ser um guia, em especial nos anos iniciais de trabalho.

Sarmento e Lamberts (2017) refletem sobre o papel do professor no que concerne ao processo de escolha e avaliação de LDs. As autoras chegam à conclusão de que "o professor tem papel decisivo nas diferentes esferas que envolvem o livro didático (implementação, avaliação/escolha, uso e adaptação) (p. 291)", reforçando mais uma vez a importância de investimento na formação do professor, de modo que o processo de utilização do LD seja coerente com a prática desse profissional.

Nesse sentido, esta pesquisa propõe um viés diferente com relação às anteriores, pois investiga as crenças ${ }^{3}$ dos próprios formadores de professores quanto à utilização do LD em cursos de Letras-Inglês. Barcelos (2006) define crenças como "uma forma de pensamento, como construções da realidade, maneiras de ver e perceber o mundo e seus fenômenos (p. 16)". Nossas crenças interferem na maneira como agimos, tanto consciente quanto inconscientemente. Ainda segundo a autora, a identificação de crenças é o primeiro passo para compreendê-las. Ao investigarmos as percepções de professores, buscamos refletir sobre a coerência do uso (ou não uso) do LD nesse contexto, levando-se em conta as teorias atuais de ensino e as possíveis implicações desse uso para a formação crítica dos futuros docentes.

Assim sendo, na próxima seção apresentamos a metodologia deste trabalho, através da qual procuramos achar respostas para nossas inquietações.

\footnotetext{
${ }^{3}$ Neste trabalho entendemos 'crenças' e 'percepções' como sinônimos.
} 


\section{METODOLOGIA DA PESQUISA}

A partir de nossas experiências (tanto acadêmicas quanto profissionais) em cursos de graduação em universidades estaduais do Paraná, decidimos delimitar o escopo da pesquisa para este contexto. De modo a entender as percepções dos professores dessas Instituições de Ensino Superior (doravante IES) sobre o uso de livro didático nas disciplinas de LI em seus respectivos cursos de Letras, optamos pelo questionário via Google Forms como instrumento de coleta de dados por possibilitar preenchimento rápido, eficaz e de maior alcance.

Primeiramente realizou-se uma pesquisa on-line para verificar quantos e quais eram estes cursos, e se ofertavam licenciatura única (Letras Inglês) ou dupla (Letras Inglês/Português). As universidades e campi encontrados foram, respectivamente: Universidade Estadual de Londrina (UEL), Universidade Estadual de Maringá (UEM), Universidade Estadual do Norte do Paraná (UENP, campi Cornélio Procópio e Jacarezinho), Universidade Estadual de Ponta Grossa (UEPG), Universidade Estadual do Paraná (Unespar, campi Apucarana, Campo Mourão, Paranaguá, Paranavaí e União da Vitória), Universidade Estadual do Centro-Oeste (Unicentro, campi Irati e Santa Cruz) e Universidade Estadual do Oeste do Paraná (Unioeste, campi Cascavel, Foz do Iguaçu e Marechal Cândido Rondon).

Das sete IES, duas ofertam licenciatura única em Inglês: a UEL $^{4}$ e a Unicentro $^{5}$. A UEM oferece licenciatura única e licenciatura dupla, pois são dois cursos diferentes ${ }^{6}$ : Inglês e Literaturas correspondentes (Licenciatura e Bacharelado) e Português/Inglês e Literaturas correspondentes, respectivamente. A Unespar também oferece licenciatura única ${ }^{7}$ e licenciatura dupla ${ }^{8}$.

\footnotetext{
${ }^{4}$ Informações sobre o curso disponíveis no link: $<$ http://www.uel.br/col/lem/portal/pages/letrasingles.php>. Acesso em: 28 ago. 2019.

${ }^{5}$ Informações sobre o curso disponíveis no link: <https://www2.unicentro.br/proen/files/2017/12/ Letras-G.pdf?x34126>. Acesso em: 28 ago. 2019.

${ }^{6}$ Informações sobre o curso disponíveis no link: $<$ http://www.dlm.uem.br/index.php?conteudo= grade>. Acesso em: 28 ago. 2019.

${ }^{7}$ Informações sobre o curso disponíveis no link: http://www.fecea.br/mostrar_curso.php?id=17. Acesso em: 28 ago. 2019.

${ }^{8}$ Informações sobre o curso disponíveis no link: http://paranagua.unespar.edu.br/graduacao/ letras/estrutura-letras. Acesso em: 29 ago. 2019.
} 
Já a UENP 9 , a Unioeste ${ }^{10}$ e a $U_{E P G}{ }^{11}$ oferecem apenas licenciatura dupla.

O passo seguinte envolveu pesquisar as ementas desses cursos. Abarcamos como possibilidade todas as disciplinas que tratavam da Língua Inglesa de forma geral (Língua Inglesa I, II, III e IV, por exemplo) ou de maneira mais específica (Produção/Compreensão Escrita/Oral em Língua Inglesa). Professores de disciplinas de Literaturas de Língua Inglesa e/ou abordagens/métodos de ensino, por exemplo, não foram contemplados. Escolhemos focar no inglês por ser esta a língua com a qual trabalhamos.

Uma vez delimitado o contexto de pesquisa e o perfil dos participantes, passamos para a produção do questionário ${ }^{12}$. Interessou-nos averiguar as seguintes questões: qual a universidade e campus em que o docente trabalha e se nesse contexto se utiliza um LD; quais critérios embasaram a escolha dos materiais didáticos usados em seu curso (sejam eles LDs ou não); quais os pontos positivos e negativos de se utilizar um $\mathrm{LD}$, na opinião do docente; e se ele/ela teria disponibilidade para participar de uma entrevista de modo a esclarecer e/ou aprofundar algumas das respostas dadas.

Para agilizar o preenchimento do questionário, decidimos incluir múltiplas opções de resposta para cada pergunta, as quais não eram autoexcludentes, isto é, o docente poderia selecionar quantas alternativas lhe parecesse pertinente. Além disso, incluímos para todas as perguntas a opção de resposta 'Outros', que permitia ao professor tecer seus próprios comentários e considerações. As opções de resposta foram desenvolvidas com base no trabalho de diversos autores (LAMBERTS, 2015; PESSOA, 2009; RAMOS, 2009; SOUZA; STEFANELLO; SPILMANN, 2010) e também de acordo com nossa própria experiência como professoras.

A primeira pergunta, que pediu aos participantes para identificarem a universidade e campus em que trabalham, e a segunda, que averiguou se no contexto em questão se utiliza ou não de um LD, nos ajudaram a traçar um panorama da presença dessa ferramenta didática nas IES do Paraná.

\footnotetext{
${ }^{9}$ Informações sobre o curso disponíveis no link: https://uenp.edu.br/letras-ingles. Acesso em: 28 ago. 2019.

${ }^{10}$ Informações sobre o curso disponíveis no link: https://www5.unioeste.br/portal/prograd-outros/ cursos-campus-todos/cascavelcursos?campi=0\&curso=CSC0022. Acesso em: 29 ago. 2019.

${ }^{11}$ Informações sobre o curso disponíveis no link: http://www.uepg.br/catalogo/cursos/2016/ LicLetrasPortIngles.pdf. Acesso em: 30 ago. 2019.

${ }^{12}$ Disponível no Apêndice B.
} 
Ainda que originalmente tivemos como intenção desenvolver apenas um questionário, percebemos que uma resposta afirmativa ou negativa à segunda pergunta (se o curso utiliza ou não LD) acarretaria um conjunto de perguntas diferentes para esses dois grupos - mesmo que os objetivos originais das perguntas fossem mantidos. Por exemplo, no caso de resposta afirmativa (ou seja, há o uso de LD), o docente responderia à seguinte pergunta:

5. Na sua opinião, quais os pontos positivos de se utilizar um livro didático? Selecione uma ou mais respostas que se aplicam.

( ) facilidade/agilidade na preparação de aulas

( ) maior alinhamento entre professores que ensinam diferentes níveis e turmas

( ) respaldo de uma instituição ou órgão (ex. Quadro Europeu Comum de Referência)

( ) roteiro pré-estabelecido de unidades e conteúdos

( ) outros (especifique):

No caso de uma resposta negativa, a pergunta seria a mesma, apenas de um ponto de vista diferente, como se percebe pelo exemplo a seguir:

5. Quais os pontos negativos de não se utilizar livro didático? Selecione uma ou mais respostas que se aplicam.

( ) falta de alinhamento entre professores quanto aos conteúdos a serem ensinados nos diversos níveis

( ) falta de respaldo de uma instituição ou órgão (ex. Quadro Europeu Comum de Referência)

( ) falta de um roteiro pré-estabelecido de unidades e conteúdos

( ) mais tempo gasto na preparação de aulas

( ) outros (especifique):

Decidimos prezar pelo ponto de vista dos respondentes - e, portanto, ramificar o questionário, como exemplificado acima - para que suas respostas se aproximassem ao máximo de seu contexto de trabalho atual. O questionário contou, no total, com seis perguntas para quem respondeu que não utiliza um LD e sete perguntas para quem o utiliza, uma vez que uma das perguntas era sobre o nome do livro utilizado.

O questionário foi enviado via $e-$ mail $^{13}$ aos Colegiados dos cursos em novembro de 2018. Devido ao baixo número de respostas, um lembrete foi enviado em abril de 2019, e no mês seguinte encerramos o aceite de novas respostas.

\footnotetext{
${ }^{13}$ Disponível no Apêndice A.
} 
Pode-se classificar esta pesquisa como quantitativa pelo fato de utilizar uma ferramenta de coleta que gera, principalmente, dados numéricos. Ainda assim, todas as perguntas abarcaram ao menos uma opção de resposta aberta, e mesmo dados numéricos precisam ser interpretados à luz de teorias e de objetivos de pesquisa; eles não são autoevidentes.

Na seção seguinte, apresentamos e analisamos os dados coletados.

\section{ANÁLISE DAS RESPOSTAS}

Obtivemos retorno de seis das sete universidades que receberam nosso questionário, provenientes de oito campi diferentes e totalizando dez respondentes. De modo a proteger a identidade dos professores desses cursos, demos preferência por manter o anonimato das IES.

Para a primeira pergunta do questionário, "No curso de Letras-Inglês ou Letras Português-Inglês no qual trabalha, é solicitada a utilização de um livro didático prédeterminado para o ensino de língua inglesa?", três dos oito campi relataram utilizar um LD, ao passo que cinco não o fazem. Nas próximas subseções, analisamos separadamente as respostas afirmativas (Cursos que adotam um livro didático para o ensino de língua inglesa) e negativas (Cursos que não adotam um livro didático para o ensino de língua inglesa), respectivamente, a essa pergunta.

\section{Cursos que adotam um livro didático para o ensino de língua inglesa}

Em relação aos cursos que utilizam um LD, esses livros são (pergunta 3): Interchange (editora Cambridge; à época de resposta ao questionário, ocorria mudança gradual para o livro American English File - editora Oxford), North Star (editora Pearson) e Global (editora Macmillan). Pelo fato do número de respondentes não ter sido grande, preferimos descrever suas respostas ao invés de apresentar gráficos e resultados percentuais, entendendo que a amostragem pequena limita nossas interpretações.

Em relação aos critérios que embasaram a escolha do LD (pergunta 4), a adequação ao programa da disciplina, a possibilidade de contato com diversos gêneros textuais, a presença de temas interessantes e atuais, bem como a utilização e integração das quatro habilidades (reading, listening, speaking, writing) foram critérios selecionados pelos três respondentes. Já a adequação ao nível de proficiência exigido pelo Projeto Pedagógico do Curso (doravante PPC) foi apontada por dois deles, ao passo que o estímulo ao pensamento 
crítico foi selecionado por apenas um.

Percebe-se que, embora o PPC seja o documento-guia de um curso de graduação, os professores parecem se pautar mais nos programas de disciplina, ferramentas passíveis de adaptação por parte de cada professor que ministra uma matéria. Apesar de entendermos o PPC e o programa como documentos complementares, também reconhecemos que, sendo escritos por pessoas diferentes com propósitos diferentes, estão sujeitos a eventuais discrepâncias, e por esse motivo eles foram separados nas opções de resposta do questionário.

Em seu trabalho no âmbito da avaliação, Silva e Furtoso (2017) mostram, por exemplo, que há um certo distanciamento do ponto de vista da coerência entre o PP do curso de Letras da UEL e os programas das disciplinas dos professores formadores. Dos 28 programas analisados, 25 faziam uso do instrumento de avaliação 'prova', sendo que o PP do curso proporcionava uma visão muito mais flexível, possibilitando o uso de diversas ferramentas avaliativas. Para as autoras, a prova não deixa de ser um instrumento legítimo; no entanto, elas questionam sua utilização como única ferramenta avaliativa em um contexto de formação de professores.

O estímulo ao pensamento crítico foi apontado por apenas um respondente, ao passo que a integração das quatro habilidades foi escolhida por todos eles. Isso pode indicar uma procura por LDs que foquem mais na comunicação do que no pensamento crítico e na agência social, elementos priorizados pelos documentos oficiais brasileiros, mas não necessariamente pelas editoras estrangeiras dos livros elencados. $\mathrm{O}$ fato de que a adequação à noção de linguagem no PPC não foi um critério escolhido por nenhum dos três respondentes vai ao encontro deste dado, isto é, a concepção de língua(gem) defendida nos documentos oficiais (como seria o caso de um PPC) pode não estar sendo considerada na escolha de LDs. Este é um dado preocupante, já que, como discutido anteriormente, a visão de língua(gem) é um fator norteador das ações dos professores formadores.

Reforçamos aqui que o LD é um veículo de ideologias e visões de mundo, podendo assim influenciar a identidade dos aprendizes (SOUZA; MATE; PORTO, 2011; TÍLIO, 2008). Parece-nos que, nos contextos aqui analisados, existe uma preponderância da abordagem comunicativa, visto que as quatro habilidades estão contempladas nos critérios de seleção, mas não o estímulo ao pensamento crítico ${ }^{14}$. Ainda assim, é importante

\footnotetext{
${ }^{14}$ De acordo com Sumner (1940), ter um pensamento crítico significa testar e examinar todo e qualquer tipo de afirmação a fim de descobrir se tal proposição corresponde à realidade ou não. O pensamento crítico é um produto de educação e treino. Para o autor, a boa educação é apenas
} 
ressaltar que a abundância de exercícios gramaticais foi um critério ignorado pelos três respondentes, o que já aponta para o afastamento de uma visão estruturalista de língua.

A facilidade de acesso ao material (devido ao preço ou disponibilidade em livrarias) também não é um fator relevante na escolha de LDs nesses contextos. Porém, se considerarmos o perfil socioeconômico do estudante de Letras, além do fato dessas instituições serem públicas, talvez esse critério devesse ser incluído, uma vez que LDs muito caros ou de disponibilidade limitada (o que também encarece o frete, por exemplo), podem ser opções inviáveis para alguns discentes.

Quanto à pergunta 5, referente aos pontos positivos de se utilizar um LD, todas as opções de resposta foram escolhidas ao menos uma vez e no máximo duas - isto é, nenhuma delas foi escolhida pelos três respondentes ao mesmo tempo. Os itens que sobressaíram foram o maior alinhamento entre professores que ensinam diferentes níveis e turmas e o roteiro pré-estabelecido de unidades e conteúdos. Facilidade na preparação de aulas e respaldo de uma instituição ou órgão (como o Quadro Europeu Comum de Referência) foram escolhidos uma vez. Um dos respondentes adicionou às opções e afirmou que poder utilizar diferentes variedades do inglês em uma perspectiva de língua franca é uma das vantagens do LD; porém, este deve ser utilizado como suporte, não como recurso principal, em sua opinião.

Em relação aos pontos negativos do LD (pergunta 6), todas as respostas também foram contempladas ao menos uma vez e no máximo duas. O fato do LD nem sempre ser condizente com o contexto e exigir investimento financeiro por parte dos alunos foram as respostas mais escolhidas. É interessante notar que, embora o preço do LD ganhe destaque como ponto negativo, ele ainda não é considerado um critério de escolha pelos professores, como vimos nos parágrafos anteriores. A limitação na criatividade do professor e na flexibilidade de planejamento de aulas foram respostas marcadas uma vez, o que pode ser um indicativo de que os docentes não se sentem presos ao LD.

A seguir, passaremos para as percepções dos professores cujos cursos não utilizam um LD.

\section{Cursos que não adotam um livro didático para o ensino de língua inglesa}

Em cinco dos oito campi não há um LD pré-estabelecido. Todos os sete respondentes apontaram que a divisão de conteúdos de língua inglesa ao longo da graduação (pergunta

aquela capaz de formar seres humanos críticos. 
3) é feita com base no que é previsto pelo programa da disciplina, e três assinalaram que essa divisão é feita com base no PPC.

Mais uma vez, nota-se que os professores se apoiam principalmente no programa da disciplina para fazer a escolha do material didático sendo que, de fato, é a partir do PPC, de sua visão de língua e aprendizagem-avaliação-ensino, que se constrói esse programa. Um dos respondentes afirmou que cada professor faz sua própria seleção de material didático (de acordo com o perfil ou necessidades da turma, por exemplo) e outro, pelo contrário, apontou que a divisão é feita

com discussão conjunta dos professores que lecionam todas as disciplinas de Língua, de Literatura e de Formação, para encontrarmos pontos em que uma disciplina possa "conversar" com a outra, complementando e/ ou possibilitando que os licenciados possam estabelecer interconexões entre os vários saberes que constituem o fazer docente (RESPONDENTE E, 2019).

Embora o professor deva ser capaz de tomar decisões bem-informadas por conta própria, o compartilhamento de informações pode enriquecer a prática pedagógica e auxiliar no alinhamento do trabalho de um mesmo departamento ou curso, além de incentivar a interdisciplinaridade, de acordo com o Respondente E. Além disso, a reflexão coletiva, em oposição à individual, põe em evidência as singularidades do contexto onde trabalham os professores, sendo um recurso defendido no novo modelo de formação de professores (PESSOA, 2009). Quanto aos pontos positivos da não-utilização de LD (pergunta 4), três respostas foram escolhidas por seis dos sete professores, a saber: a possibilidade de maior flexibilidade na escolha de materiais e conteúdos, a utilização de materiais mais atuais e condizentes com o contexto e o baixo investimento financeiro por parte dos alunos. O incentivo à criatividade do professor foi apontado por cinco dos respondentes. Vemos, portanto, que os professores valorizam a liberdade de escolha possibilitada pela produção de materiais didáticos, além de perceberem a limitação contextual de um LD. A preocupação quanto ao investimento financeiro por parte dos alunos permanece um tema recorrente.

Um dos respondentes apontou que a não utilização do LD "permite a representação de identidades sociais de classe, raça e de gênero mais inclusivas" (RESPONDENTE B, 2019), e, de acordo com outro, 
Preparar aulas permite não apenas o desenvolvimento de criatividade, mas incentiva a especialização e a pesquisa. Penso que usar o livro didático é uma solução simplista para o ensino de LEM na universidade. Há especificidades do ensino superior que os materiais didáticos normalmente não contemplam, como a reflexão metalinguística aprofundada (RESPONDENTE C, 2019).

Pelo comentário, o Respondente $\mathrm{C}$ deixa claro que preparar material didático faz parte do que é ser professor, e pode inclusive levá-lo a refletir sobre seu trabalho. Embora não acreditemos que usar LD no Ensino Superior seja necessariamente "uma solução simplista", pois nenhum LD atenderá a todas as necessidades de um contexto (SARMENTO; LAMBERTS, 2017), exigindo, assim, adaptações, concordamos que dificilmente há LDs voltados para esse público-alvo, o que dificulta sua adoção nesses contextos.

Com relação aos pontos negativos de não se ter um LD (pergunta 5), a falta de alinhamento entre professores quanto aos conteúdos e o tempo extra gasto na preparação de aulas foram os itens mais populares, sendo escolhidos, cada um, por três dos sete professores. Esse número é apenas metade do número máximo das respostas à pergunta anterior, referente aos pontos positivos, o que já indica que os professores têm preferência pela produção do próprio material (isto é, os pontos positivos receberam o dobro de respostas que os pontos negativos). Um dos professores pontuou que

todos os itens citados [na questão 4 do questionário] são desafios a serem enfrentados nas universidades, que são instituições que oferecem respaldo para o conhecimento que multiplicam. O uso do QCE não se restringe a livros didáticos, usei e uso atividades que eu desenvolvi ou que selecionei de acordo com critérios objetivos claros orientados pelo QCE. Somos professores de LEM [Letras Estrangeiras Modernas] que foram selecionados por seu conhecimento na área e acredito que tenhamos capacidade de fazer design instrucional adequadamente (RESPONDENTE C, 2019).

O Respondente C retoma a importância de o professor usar suas capacidades e experiência para tomar decisões bem informadas na seleção e produção de materiais didáticos. Ainda assim, relembramos que, como discutido na seção 2, os cursos de Letras nem sempre capacitam adequadamente seus profissionais. De qualquer forma, o professor deve sempre buscar evoluir e se atualizar quanto às novas demandas de ensino.

O Respondente F também faz referência ao Quadro Europeu sob um ponto de vista diferente ao comentar que vê, pela não-utilização de LDs, "dificuldade de garantir 
ao aluno, de forma gradativa, um nível crescente de complexidade linguística, a qual é muito bem trabalhada pelos materiais didáticos elaborados com base no Quadro Europeu Comum de Referência". Vemos, aqui, que a preocupação do Respondente F oferece um contraponto à certeza do Respondente $\mathrm{C}$.

Passaremos, agora, para a seção final do artigo, na qual fazemos sugestões de encaminhamento considerando os dados aqui apresentados e analisados.

\section{CONSIDERAÇÕES FINAIS}

No início deste texto, nos propusemos a investigar as percepções de professores formadores quanto ao uso do LD no ensino de inglês em cursos de Letras das IES do Paraná - isto é, em contextos de formação de professores. A partir disso, almejávamos refletir sobre a coerência desse uso ou não uso, e suas possíveis implicações para a formação do professor segundo as demandas atuais de ensino.

Relembramos, mais uma vez, que recebemos respostas de apenas dez professores, um número pequeno se considerarmos que os oito campi para os quais enviamos o questionário devem totalizar um número muito maior de profissionais ensinando inglês. O fato de utilizarmos apenas uma ferramenta de coleta de dados é um ponto fraco do nosso trabalho; infelizmente, não tivemos tempo hábil para realizar as entrevistas que estavam previstas desde o início.

Verificamos que são poucos os cursos que utilizam LD - apenas três dos oito que responderam ao questionário, resultado que não surpreende, visto que não há LDs específicos para esse contexto. Os professores formadores embasam a escolha de material didático em instrumentos de caráter mais prático e palpável (como o programa de uma disciplina) do que em instrumentos mais teóricos e abrangentes (como o PPC). Reiteramos a importância da coerência entre a concepção de aprendizagem-avaliação-ensino do professor e seu trabalho em sala de aula, e essa concepção é, justamente, abordada no Projeto Pedagógico dos cursos.

De uma forma geral, os professores parecem estar cientes das dificuldades financeiras impostas pela adoção de um LD, mesmo que nem sempre considerem este como um critério de escolha. Atividades gramaticais não são o foco na escolha de LDs, mas sim, a integração das quatro habilidades. O estímulo ao pensamento crítico ainda não é um critério priorizado. Os professores que não utilizam LD valorizaram a liberdade de escolha possibilitada pela criação de materiais didáticos, e enfatizaram as especificidades do Ensino Superior, raramente contempladas por LDs. Ainda assim, alguns profissionais 
se preocupam com a progressão dos conteúdos e a gradação da complexidade linguística, aspectos dificultados sem um LD.

Partindo da premissa que um LD nunca será perfeito, independente de quão completo e complexo seja (SARMENTO; LAMBERTS, 2017), e que o professor crítico e reflexivo deva ser capaz de desenhar seu próprio material didático ou adaptar materiais já existentes (PESSOA, 2009), trazemos, em seguida, algumas sugestões de encaminhamento que podem servir de base tanto para a escolha quanto para a criação de materiais didáticos para o ensino de inglês em licenciaturas.

Primeiramente, consideramos relevante o estabelecimento de critérios para análise do material (SARMENTO; LAMBERTS, 2016), partindo da visão de língua(gem) proposta pelo Projeto Pedagógico do curso no qual o docente atua, já que é esta visão que embasa todas as escolhas referentes ao seu trabalho. Os objetivos de aprendizagemavaliação-ensino e o público-alvo também são aspectos indispensáveis.

Diversos autores fazem sugestões de critérios de avaliação de materiais didáticos: Dias (2009), com uma check-list para análise de LDs de língua estrangeira para o Ensino Fundamental; Cristovão (2009), com um quadro para análise de sequências didáticas; D’Almas e Passoni (2013), com um quadro para análise de material didático para Licenciaturas de LI; Oliveira e Furtoso (2009), com critérios para análise de LDs de português para falantes de outras línguas; Ramos (2009), com listas de critérios para análise de unidades, textos e atividades de LDs voltados para o Ensino Fundamental e Médio; e Silva, Parreiras e Fernandes (2015), com perguntas para análise de LDs de língua inglesa com base no Guia do Programa Nacional do Livro Didático (PNLD) para Línguas Estrangeiras Modernas de 2015; para mencionar alguns trabalhos. Reiteramos a importância do desenvolvimento de uma ferramenta de análise seja ela qual for: lista/ quadro de critérios, lista de perguntas, check-list, etc.

No caso da produção de material didático, nos parece relevante que os professores de língua inglesa se reúnam para discutir e preparar materiais juntos, de forma a alinhar seus objetivos e perspectivas. As listas de análise podem ser usadas uma vez que o material estiver pronto. Se possível, esses materiais devem ser disponibilizados em plataformas de armazenamento em nuvem como Google Drive ou Dropbox, para que professores novos ou temporários também tenham acesso a eles.

Seria interessante, inclusive, se os professores mantivessem uma planilha ou diário de classe ano após ano, caso essa já não seja uma prática adotada, de modo a registrar o que foi trabalhado em cada turma. Sabemos que a agenda corrida dos docentes nem sempre permite muitos momentos de encontro, mas acreditamos que o trabalho coletivo 
e colaborativo possa ser uma ferramenta de fortalecimento e enriquecimento da prática pedagógica.

Tendo em vista a problemática aqui apresentada, nos parece urgente a necessidade de mais trabalhos sobre o uso de LDs em cursos de formação de professores. Trabalhos futuros podem investigar outras línguas, outros Estados e/ou regiões do país, visto que nossa amostra reduzida limitou as possibilidades de interpretação dos resultados, ou apresentar tentativas de desenvolvimento de critérios, de produção de material didático específico, etc. Caso a ferramenta de investigação seja o questionário, sugerimos a inclusão de temas como identidades de classe, raça e gênero, e inglês como língua franca, aspectos apontados por nossos respondentes. Ademais, reforçamos a importância de se utilizar mais de uma ferramenta de coleta de dados, de modo a garantir a confiabilidade dos resultados.

Por fim, consideramos de extrema importância a inclusão, nos cursos de graduação, de disciplinas obrigatórias relacionadas à análise de livros/materiais didáticos. Nestes espaços os discentes podem, inclusive, ser convidados a elaborar materiais didáticos e listas de análise dos mesmos para seu próprio curso (por exemplo, alunos do terceiro ano preparam materiais e critérios para a disciplina de inglês do segundo ano, e assim por diante) como forma de exercer a autonomia, a reflexão e a criticidade.

Relembramos que a formação do profissional de Letras deve abranger mais do que técnicas de ensino e conhecimento da língua em si, sendo preciso "incluir teorias de ensino e aprendizagem, conhecimento do conteúdo e capacidade de reflexão e tomada de decisão" (PESSOA, 2009, p. 56). O investimento na formação de qualidade deste futuro professor é imprescindível (PESSOA, 2009; SARMENTO; LAMBERTS, 2016) para uma melhora na qualidade da educação brasileira. 


\section{REFERÊNCIAS:}

BAKHTIN, M. Os gêneros do discurso. In: BAKHTIN, M. Estética da criação verbal. São Paulo: Martins Fontes, 2003. p. 261-306.

BARCELOS, A. M. F. Cognição de professores e alunos: tendências recentes na pesquisa de crenças sobre ensino e aprendizagem de línguas. In: BARCELOS, A. M. F.; VIEIRAABRAHÃO, M. H. (orgs). Crenças e ensino de línguas: foco no professor, no aluno e na formação de professores. Campinas: Pontes Editores, 2006, p. 15-42.

BRASIL. Ministério da Educação. Parecer CNE/CES n 492, de 3 de abril de 2001. Institui as Diretrizes Curriculares Nacionais dos cursos de graduação em Filosofia, História, Geografia, Serviço Social, Comunicação Social, Ciências Sociais, Letras, Biblioteconomia, Arquivologia e Museologia. Diário Oficial da República Federativa do Brasil, Brasília, 9 jul. 2001. Seção 1E, p. 50.

. Resolução CNE/CP 1, de 18 de fevereiro de 2002. Institui Diretrizes Curriculares Nacionais para a Formação de Professores da Educação Básica, em nível superior, curso de licenciatura, de graduação plena. Disponível em: <http://portal.mec.gov.br/cne/ arquivos/pdf/rcp01_02.pdf>. Acesso em: 29 ago. 2019.

CONSOLO, D. A. O livro didático como insumo na aula de língua estrangeira (inglês) na escola pública. Dissertação de Mestrado. Departamento de Linguística Aplicada do Instituto de Estudos da Linguagem da Universidade Estadual de Campinas. Campinas, 1990.

CRISTOVÃO, V. L. L. Sequências Didáticas para Ensino de Línguas. In: DIAS, R.; CRISTOVÃO, V. L. L. (Org.). O Livro Didático de Língua Estrangeira: múltiplas perspectivas. Campinas: Mercado de Letras, 2009, v. 1, p. 305-344.

D’ALMAS, J.; PASSONI, T. P. Análise de um livro didático de compreensão e produção escrita: uma proposta para licenciatura em língua inglesa. Revista Eletrônica Prodocência/UEL, v. 1, n. 3, p. 65-79, 2013. Acesso em: 04 set. 2019.

DARLING-HAMMOND, L. Powerful Teacher Education: lessons from exemplary programs. San Francisco: Jossey-Bass. 2006. Capítulo 3. Adressing the dilemmas of teacher education: evidence of success, p. 42-74.

DIAS, R. Critérios para a avaliação do livro didático de língua estrangeira no contexto do segundo ciclo do Ensino Fundamental. In: DIAS, R.; CRISTOVÃO, V. L. L. (Org.). O Livro Didático de Língua Estrangeira: múltiplas perspectivas. Campinas: Mercado de Letras, 2009, v. 1, p. 199-234. 
FREIRE, P. Pedagogia do Oprimido. 14ª ed. Rio de Janeiro: Paz e Terra, 1985.

GIMENEZ, T. Reflective teaching and teacher education: contributions from teacher thinking. Linguagem e Ensino, 1999, v. 2, n. 2, p. 129-143.

HOFFMANN, J. Avaliação mito e desafio: uma perspectiva construtivista. $29^{a}$ ed. Porto Alegre: Mediação, 2000.

LAMBERTS, Denise von der Heyde. O livro didático de língua inglesa em uso: análise de pesquisas e observações de aula no programa idiomas sem fronteiras-inglês. 2015. 235f. Dissertação (Mestrado em Letras) - Universidade Federal do Rio Grande do Sul, 2015.

LEFFA, V. J. Metodologia do ensino de línguas. In: BOHN, H. I.; VANDRESEN, P. Tópicos em lingüística aplicada: O ensino de línguas estrangeiras. Florianópolis: Ed. da UFSC, 1988. p. 211-236.

LEUNG, C. et al. Using assessment to promote learning: clarifying construct, theories, and practices. In: DAVIS, J. McE.; NORRIS, J. M.; MALONE, M. E.; McKAY, T. H.; SON, Y. (Ed.). Useful assessment and evaluation in language education. Washington, D. C.: Georgetown University Press, 2018. p. 75-91.

LIBERALI, F. C. As linguagens das reflexões. In: MAGAlHÃES, M. C. C. (org.). A formação do professor como um profissional crítico. São Paulo: Mercado de Letras, 2004. p. 87-117.

OLIVEIRA, E. V. de M.; FURTOSO, V. A. B. Buscando critérios para avaliação de livros didáticos: uma experiência no contexto de formação de professores de português para falantes de outras línguas. In: DIAS, R.; CRISTOVÃO, V. L. L. (Org.). O livro didático de língua estrangeira: múltiplas perspectivas. Campinas: Mercado de Letras, 2009, v. 1, p. 235-263.

PAIVA, V. L. M. O. História do material didático de língua inglesa no Brasil. In: DIAS, R.; CRISTOVÃO, V. L. L. (Org.). O livro didático de língua estrangeira: múltiplas perspectivas. Campinas: Mercado de Letras, 2009. p. 17-56.

PESSOA, R. R. O livro didático na perspectiva da formação de professores. Trabalhos em linguística aplicada [online]. 2009, v. 48, n. 1, p. 53-69. 
RAMOS, R. C. G. O livro didático de língua inglesa para o ensino fundamental e médio: reflexões e sobre teoria e prática. In: DIAS, R.; CRISTOVÃO, V. L. L. (Org.). O livro didático de língua estrangeira: múltiplas perspectivas. Campinas: Mercado das Letras, 2009. p. 173-198.

SARMENTO, S.; LAMBERTS, Denise von der Heyde. O papel do livro didático no ensino de inglês: aspectos sobre sua importância, escolha e utilização. (CON)TEXTOS LINGUÍSTICOS, v. 10, p. 291-300, 2016.

SARMENTO, S.; LAMBERTS, Denise von der Heyde. Pesquisas sobre livros didáticos: o estado da arte. ENTRETEXTOS (UEL), v. 17, p. 333-360, 2017.

SCARAMUCCI, M. V. R. O professor avaliador: sobre a importância da avaliação na formação do professor de língua estrangeira. In: ROTTAVA, L.; SANTOS, S. R. (Orgs.) Ensino-aprendizagem de línguas: língua estrangeira. Coleção Linguagens. Ijuí: Editora da UNIJUI, 2006, p. 49-64.

SCHÖN, D. A. The reflective practitioner: how professionals think in action. USA: Basic Books, 1983.

SENISE, P. Origem do Instituto de Química: reminiscências e comentários. São Paulo: Instituto de Química da USP, 2006.

SILVA, C. S.; FURTOSO, V. B. Entre o papel de aluno e o de professor de inglês: considerações sobre a formação em avaliação nas licenciaturas. In: ARAUJO, V. C.; SILVEIRA, P. (Org.). Da teoria e da prática: o ensino de línguas estrangeiras em discussão. Campinas: Pontes, 2017. p. 43-70.

SILVA, E. T. da. Livros didáticos: do ritual de passagem a ultrapassagem. Em aberto. Brasília, 1996, p. 8-11. Disponível em: <http://www.publicacoes.inep.gov.br/ arquivos/\%7B5F8D6FDF-2BF0-476F-9271-88ADE36BAD1A\%7D_Em_Aberto_69. pdf>. Acesso em: 29 ago. 2019.

SILVA, R. C. da; PARREIRAS, V. A.; FERNANDES, G. G. M. Avaliação e escolha de livros didáticos de inglês a partir do PNLD: uma proposta para guiar a análise. Linguagem \& Ensino, Pelotas, v. 18, n. 2, p. 355-377, jul./dez. 2015.

SOUZA, A. P. R. de; STEFANELlO, C. A.; SPILMANN, I. A. A concepção sociointeracionista no ensino do inglês: o professor e o livro didático. Roteiro, v. 35, n. 1, jan./jun. 2010, p. 23-52. 
SOUZA, K. A. F. D.; MATE, C. H.; PORTO, P. A. História do uso do livro didático universitário: o caso do Instituto de Química da USP. Ciência e Educação (UNESP. Impresso), v. 17, n. 4, p. 873-886, 2011.

SUMNER, W. G. Folkways: A Study of the Sociological Importance of Usages, Manners, Customs, Mores, and Morals. New York: GinnandCo., 1940.

TÍLIO, R. O papel do livro didático no ensino de língua estrangeira. Revista Eletrônica do Instituto de Humanidades, v. 7, n. 26, jul./set. 2008.

VYGOTSKY, L. S. A formação social da mente. São Paulo: Martins Fontes, 2003. 


\section{APÊNDICE A - E-MAIL ENVIADO AOS CURSOS DE LETRAS-INGLÊS OU LETRAS PORTUGUÊS-INGLÊS DAS UNIVERSIDADES ESTADUAIS DO PARANÁ PARA DIVULGAÇÃO DA PESQUISA E DO QUESTIONÁRIO}

Prezados docentes de língua inglesa da (NOME DA UNIVERSIDADE),

Somos professoras de inglês e estamos realizando uma pesquisa relacionada ao uso de livro didático nos cursos de Letras-Inglês ou Letras Português-Inglês das universidades estaduais do Paraná.

Desenvolvemos um questionário curto, de apenas dez perguntas de múltipla escolha, com tempo de resposta de 5 a 10 minutos. Gostaríamos de contar com a participação do máximo de professores possível. Agradeceríamos se pudesse(m) divulgar este $e$-mail para todos os professores e professoras do seu departamento que ministrem disciplinas de língua inglesa.

O foco é em professores que ministrem língua inglesa geral, como por exemplo as disciplinas de X, Y e Z da grade curricular do seu curso de Letras.

Estamos à disposição para qualquer dúvida, e pretendemos divulgar o artigo final quando publicado.

Link para o questionário: https://goo.g1/forms/Y35soQiZB3LyDwmf1

Atenciosamente,

Elisângela L. Liberatti e Isadora T. Moraes. 


\section{APÊNDICE B - QUESTIONÁRIO SOBRE O USO (OU NÃO) DE LIVRO DIDÁTICO PARA O ENSINO DE INGLÊS NOS CURSOS DE LETRAS-IN- GLÊS OU LETRAS PORTUGUÊS-INGLÊS DAS UNIVERSIDADES ESTA- DUAIS DO PARANÁ}

O objetivo deste questionário é realizar o mapeamento do uso (ou não uso) de livro didático nas licenciaturas únicas e/ou duplas (Letras-Inglês, Letras Português-Inglês) das universidades estaduais do Paraná de modo a: a) traçar o perfil das universidades quanto ao uso de livro didático; b) fazer uma discussão sobre as razões que embasam seu uso (ou não uso); c) discutir os prós e contras de se ter ou não ter livro didático no contexto universitário.

São apenas algumas perguntas de múltipla escolha. Não há intenção de julgar as respostas como certas ou erradas, mas de compreender determinadas escolhas e os motivos por trás delas. Assim, pedimos que responda as perguntas abaixo o mais verdadeira e detalhadamente possível.

Os resultados serão divulgados em um artigo que será produzido pelas autoras e que será enviado para apreciação, uma vez terminado. Seu nome não será divulgado, apenas o da instituição.

Obrigada pela participação!

1.Você trabalha em qual universidade (e campus, quando aplicável)?
( ) UEL
( ) UEM
( ) UENP (Cornélio Procópio)
( ) UENP (Jacarezinho)
( ) UEPG
( ) UNESPAR (Apucarana)
( ) UNESPAR (Campo Mourão)
( ) UNESPAR (Paranaguá)
( ) UNESPAR (Paranavaí)
( ) UNESPAR (União da Vitória)
( ) UNICENTRO (Irati)
( ) UNICENTRO (Santa Cruz)
( ) UNIOESTE (Cascavel) 
( ) UNIOESTE (Foz do Iguaçu)

( ) UNIOESTE (Marechal Cândido Rondon)

2. No curso de Letras-Inglês ou Letras Português-Inglês no qual trabalha, é solicitada a utilização de um livro didático pré-determinado para o ensino de língua inglesa?

( ) Sim - responda às perguntas na categoria SIM logo abaixo

( ) Não - responda às perguntas na categoria NÃO mais abaixo

\section{PARA OS PARTICIPANTES QUE SELECIONARAM A OPÇÃO "SIM" NA PRIMEIRA QUESTÃO (PERGUNTAS 3 A 7 A SEGUIR):}

3. Qual livro (ou material didático) é utilizado (ex. nome do livro/série de livros e editora)?

4. Quais critérios embasaram a escolha desse livro/material didático? Selecione uma ou mais respostas que se aplicam.

( ) abundância de exercícios gramaticais

( ) adequação à noção de língua(gem) segundo o PPC

( ) adequação ao nível de proficiência exigido pelo PPC

( ) adequação ao programa da disciplina

( ) estímulo ao pensamento crítico

( ) material de fácil acesso (devido ao preço ou disponibilidade nas livrarias da cidade)

( ) possibilidade de contato com diversos gêneros textuais

( ) presença de temas interessantes/atuais

( ) utilização e integração das quatro habilidades (reading, listening, speaking, writing)

( ) outros (especifique):

5. Na sua opinião, quais os pontos positivos de se utilizar um livro didático? Selecione uma ou mais respostas que se aplicam.

( ) facilidade/agilidade na preparação de aulas

( ) maior alinhamento entre professores que ensinam diferentes níveis e turmas

( ) respaldo de uma instituição ou órgão (ex. Quadro Europeu Comum de 


\section{Referência)}

( ) roteiro pré-estabelecido de unidades e conteúdos

( ) outros (especifique):

6. Quais os pontos negativos de se utilizar um livro didático? Selecione uma ou mais respostas que se aplicam.

( ) não permite tanta flexibilidade no planejamento de aulas e atividades

( ) nem sempre é condizente com o contexto de atuação (em relação a nível, temas, etc.)

( ) exige investimento financeiro por parte dos alunos

( ) limita a criatividade do professor

( ) outros (especifique):

7. Caso necessário, você teria disponibilidade para participar de uma entrevista (ao vivo ou por Skype) de duração média de 5 a 10 minutos?
( ) $\operatorname{Sim}$
( ) Não

\section{PARA OS PARTICIPANTES QUE SELECIONARAM A OPÇÃO "NÃO" NA PRIMEIRA QUESTÃO (PERGUNTAS 3 A 6 A SEGUIR):}

3. Como é feita a divisão de conteúdos de língua inglesa ao longo da graduação? Selecione uma ou mais respostas que se aplicam.

( ) com base no que é previsto pelo PPC

( ) com base no que é previsto pelo programa da disciplina

( ) cada professor faz sua própria seleção (de acordo com o perfil ou necessidades da turma, por exemplo)

( ) outros (especifique):

4. Na sua opinião, quais os pontos positivos de não se utilizar um livro didático? Selecione uma ou mais respostas que se aplicam.

( ) permite maior flexibilidade por parte dos professores na escolha de materiais e conteúdos

( ) permite a utilização de materiais mais atuais e condizentes com o contexto (ex. notícias) 
( ) não exige grande investimento financeiro por parte dos alunos

( ) incentiva a criatividade do professor

( ) outros (especifique):

5. Quais os pontos negativos de não se utilizar livro didático? Selecione uma ou mais respostas que se aplicam.

( ) falta de alinhamento entre professores quanto aos conteúdos a serem ensinados nos diversos níveis

( ) falta de respaldo de uma instituição ou órgão (ex. Quadro Europeu Comum de Referência)

( ) falta de um roteiro pré-estabelecido de unidades e conteúdos

( ) mais tempo gasto na preparação de aulas

( ) outros (especifique):

6. Caso necessário, você teria disponibilidade para participar de uma entrevista (ao vivo ou por Skype) de duração média de 5 a 10 minutos?
( ) $\operatorname{Sim}$
( ) Não

Recebido em: 26 set. 2019 Aceito em: 14 abr. 2020 